\title{
Educação Física escolar em tempos de pandemia: $O$ trabalho em uma escola com jogos e brincadeiras tradicionais durante o Regime Especial de Atividades não Presenciais na rede estadual de ensino de Minas Gerais
}

\author{
School Physical Education in pandemic times: Working in a school with traditional \\ games during the Special Regime of Outstanding Activities in the state network of \\ Minas Gerais teaching
}

Filipe Gabriel Ribeiro França ${ }^{1}$, Luciana de Freitas Gomes ${ }^{2}$

\begin{abstract}
RESUMO: O presente trabalho tem como objetivo relatar as experiências desenvolvidas pelo componente curricular Educação Física com os jogos e brincadeiras tradicionais durante o regime especial de atividades não presenciais proposto pela rede estadual de ensino de Minas Gerais. As experiências relatadas foram vivenciadas nas aulas de Educação Física por turmas dos Anos Iniciais do Ensino Fundamental em uma escola pública estadual na cidade de Juiz de Fora - MG. Em diálogo com os estudantes e responsáveis foram apresentadas propostas de jogos e brincadeiras tradicionais que pudessem ser realizados em casa, tendo em vista o contexto de isolamento social decorrente da pandemia de Covid-19 ocorrido no ano escolar de 2020. As atividades sugeridas levaram em consideração a possibilidade a adaptação do espaço para as suas vivências e a construção de materiais alternativos e adaptados com recursos presentes em casa quando necessário. Metodologicamente tomamos os jogos e brincadeiras tradicionais como um dos saberes que devem ser trabalhados nas aulas de Educação Física escolar, ressaltando a importância de observarmos a cultura popular presente no contexto regional e comunitário, assumindo-a enquanto construção cultural, histórico e social. Nessa abordagem sobre os jogos e brincadeiras tradicionais os estudantes foram capazes de se expressarem conscientemente e realizarem reflexões críticas sobre como as práticas eram vivenciadas no passado e na atualidade e puderam compreender a importância do movimento e da continuidade das atividades Educação Física escolar mesmo à distância.
\end{abstract}

PALAVRAS-CHAVE: Educação Física escolar; Jogos e brincadeiras tradicionais; Regime Especial de Atividades Não Presenciais.

\begin{abstract}
This work aims to report the experiences developed by the Physical Education curricular component with traditional games during the Special Regime of Outstanding Activities proposed by the state school system in Minas Gerais. The reported experiences were lived in Physical Education classes by groups of the Early Years of Elementary School in a state public school in the city of Juiz de Fora - MG. In dialogue with students and guardians, proposals for traditional games that could be performed at home were presented, in view of the context of social

\footnotetext{
1 Professor de Educação Física na Rede Estadual de Ensino de Minas Gerais e na Rede Municipal de Ensino de Juiz de Fora - MG, Doutor em Educação. ORCID id: 0000-0002-1557-7908. E-mail: filipe.franca@educacao.mg.gov.br

${ }^{2}$ Professora de Educação Física na Rede Estadual de Ensino de Minas Gerais, Mestra em Educação Física. ORCID id: 0000-0003-4613-7961. E-mail: luciana.freitas.gomes@educacao.mg.gov.br
} 
isolation resulting from the Covid-19 pandemic that occurred in the 2020 school year. The suggested activities took into account the possibility of adapting the space for their experiences and the construction of alternative materials and adapted with resources present at home when necessary. Methodologically we take traditional games as one of the knowledge that should be worked on in Physical Education classes at school, emphasizing the importance of observing the popular culture present in the regional and community context, assuming it as a cultural, historical and social construction. In this approach to games and traditional games the students were able to express themselves consciously and carry out critical reflections on how practices were experienced in the past and today and were able to understand the importance of movement and continuity of school Physical Education activities even from a distance.

KEYWORDS: School Physical Education; Traditional games; Special Regime of Outstanding Activities.

\section{INTRODUÇÃO}

Em virtude do avanço da pandemia de Covid-19, as aulas presenciais na rede estadual de ensino de Minas Gerais foram suspensas a partir do dia 18 de março de 2020, seguindo assim até o momento de escrita do presente texto em novembro de 2020. Pensando na continuidade do ano escolar, a Secretaria de Estado de Educação de Minas Gerais instituiu o Regime Especial de Atividades Não Presenciais (REANP) que teve início no dia 18 de maio de 2020. No REANP foram oferecidos aos estudantes e professores os seguintes materiais: Planos de Estudos Tutorados $(\mathrm{PETs})^{3}$, programa de televisão "Se liga na Educação" exibido na Rede Minas e o aplicativo para celular "Conexão Escola" destinado à comunicação entre estudantes, professores, pais, mães e demais responsáveis, além de possibilitar que os PETs fossem baixados no formato digital e o acesso às videoaulas transmitidas pela Rede Minas. Os dois primeiros volumes dos PETs dos Anos Iniciais do Ensino Fundamental contemplaram apenas os componentes curriculares Língua Portuguesa e Matemática. Portanto, nós, enquanto professores de Educação Física, tivemos a possibilidade de criar as atividades que enviaríamos aos estudantes.

A experiência pedagógica que será relatada aqui aconteceu em uma escola de Anos Iniciais do Ensino Fundamental da cidade de Juiz de Fora - MG que tem a tradição de trabalhar com projetos durante o ano letivo. Estes englobam os diversos componentes curriculares e áreas, procurando sempre tornar a construção do conhecimento algo atrativo e que desperte a curiosidade

\footnotetext{
${ }^{3}$ Os Planos de Estudos Tutorados (PETs) são uma das ferramentas do Regime Especial de Atividades Não Presenciais (REANP), desenvolvidos pela Secretaria de Estado de Educação de Minas Gerais. Eles foram ofertados aos estudantes da rede pública como alternativa para a continuidade no processo de ensino e aprendizagem no período em que as aulas presenciais estiveram suspensas por tempo indeterminado como medida de prevenção da disseminação da Covid-19 em Minas Gerais. Os PETs foram organizados por segmento de ensino, sendo ofertados materiais escritos específicos para a Educação Infantil, Anos Iniciais do Ensino Fundamental, Anos Finais do Ensino Fundamental, Ensino Médio, Ensino Médio Profissional, Educação Indígena Maxakali e Educação Especial. Cada PET é composto por quatro semanas de conteúdos a serem trabalhados por cada componente curricular.
} 
nos estudantes. Nesse sentido, com o componente curricular Educação Física não poderia ser diferente. Trabalhamos com diferentes projetos ${ }^{4}$ no decorrer dos anos escolares nos Anos Iniciais do Ensino Fundamental que nos ajudam a atingir os nossos objetivos e metas almejados na abordagem das práticas corporais, sempre buscando a participação ativa não só dos estudantes, mas também de toda comunidade escolar. A experiência pedagógica foco deste texto foi vivenciada pelas 18 turmas da escola ( 9 no turno da manhã e 9 no turno da tarde), contemplando aproximadamente 510 crianças e teve a duração de pouco mais de dois meses (de 18/05/2020 a 24/07/2020), totalizando, em média, 18 aulas ministradas em cada turma.

Um desses projetos trabalhados já há alguns anos na escola chama-se "Jogos e brincadeiras tradicionais" e é desenvolvido por nós, professores de Educação Física junto às turmas dos Anos Iniciais do Ensino Fundamental. Nele exploramos jogos e brincadeiras com as crianças assumindoas enquanto produtoras de cultura e conhecimento no espaço escolar. Inicialmente as crianças fazem entrevistas em casa com adultos e trazem para a aula os jogos e brincadeiras realizados por essas pessoas na infância. Em seguida, vivenciamos tais jogos e brincadeiras tradicionais durante as aulas e, por fim, produzimos uma pasta contendo os registros encontrados pelas crianças acerca da experiência com esses jogos e brincadeiras e expomos esses materiais para que toda a comunidade escolar tenha acesso ao que foi produzido pelas crianças.

Por tratar-se de um projeto com grande participação e integração, não só dos alunos, que se encantam com as descobertas, mas também das famílias que se recordam e se sentem satisfeitas em compartilhar suas lembranças, achamos importante darmos continuidade a ele durante o a vigência do REANP que vigorou na rede estadual de ensino de Minas Gerais em virtude da pandemia de Covid-19 no ano de 2020.

Reconhecemos que o ensino remoto tem se apresentado como um grande desafio para a comunidade escolar, principalmente para a rede pública de ensino. Nesse sentido, vivenciamos alguns aspectos desafiadores que surgiram ao longo da experiência pedagógica como, por exemplo, o acesso dos alunos às discussões e materiais disponibilizados. Na escola em questão, cerca de $90 \%$ dos estudantes conseguiram acompanhar e participar das atividades utilizando algum dispositivo eletrônico (computador, tablet ou celular). Os alunos que não puderam acompanhar as atividades propostas de forma remota receberam em casa a cada mês, via Correios, apostilas impressas contendo as atividades desenvolvidas remotamente com os demais alunos e as devolviam para a escola com os registros escritos e imagéticos referentes às atividades trabalhadas. Diante desses

\footnotetext{
${ }^{4}$ Dentre os projetos desenvolvidos pelo componente curricular Educação Física em nossa escola podemos citar: Jogos e brincadeiras tradicionais durante os cinco anos dos Anos Iniciais do Ensino Fundamental, Ensino de Xadrez (4 ${ }^{\circ}$ ano), Festival de Esportes ( $4^{\circ}$ e $5^{\circ}$ ano) e Jogos de cartas e da mente $\left(5^{\circ}\right.$ ano).
} 
dados e ao longo do desenvolvimento das aulas notamos que grande parte dos alunos conseguiram acompanhar as atividades propostas e demonstraram grande interesse por elas. Identificamos também três perfis de participação nas atividades: alunos assíduos e que sempre nos davam retorno, sendo esses a maioria de nossos estudantes; alunos que participavam apenas de algumas atividades e os alunos que receberam as atividades impressas, no formato de apostila.

\section{FUNDAMENTAÇÃO TEÓRICA}

Tizuco Morchida Kishimoto (2003) e Nelson Carvalho Marcellino (2012) enfatizam que ao levar os jogos e brincadeiras tradicionais para a escola, o professor poderá proporcionar aos alunos vivências lúdicas e culturais, que podem contar um pouco sobre as características de cada região e contexto em que os mesmos estão inseridos. Nessas vivências, ainda de acordo com os autores acima mencionados, é possível contribuir para o desenvolvimento cognitivo, social e afetivo dos sujeitos envolvidos. Como afirma Jocimar Daolio (1998), é importante não restringir as aulas de Educação Física à somente reprodução do esporte, mas sim, como uma forma de refletir as possibilidades sociais do meio e de adequar a prática a realidade de cada escola.

Vamos percebendo que a prática dos jogos e brincadeiras tradicionais vem diminuindo na atualidade. Atentamos ao fato da diminuição dos espaços urbanos, da dificuldade em encontrar locais públicos como praças e quadras e ao aumento da violência nas ruas como pontos que podem ter contribuído para essa questão. Outros fatores a serem observados são o aumento do interesse pelos artefatos culturais midiáticos (FISCHER, 2002), o surgimento e expansão da internet e a rápida proliferação dos jogos eletrônicos nos dias atuais.

Também nos fundamentamos teoricamente nas ideias propostas pelo Coletivo de Autores (2012) no final da década de 1980 e início da década de 1990, acerca da metodologia do ensino da Educação Física na escola, pensando e valorizando principalmente o conceito de cultura corporal proposto por eles/elas. Porém, entendemos que a proposta trazida pelo Coletivo de Autores (2012) é datada e diz de um contexto histórico que foi muito importante para a Educação Física brasileira. Por isso, também fazemos o exercício de pensar para além desses/as autores/as e trazemos para dialogar conosco outros sujeitos e ideias, entendendo que o diálogo enriquece o nosso olhar e nos fornece outras lentes para enxergamos as nossas práticas com a Educação Física escolar e com o ensino dos jogos e brincadeiras tradicionais. Dentre esses sujeitos destacamos Jocimar Daolio (2013) e seus trabalhos sobre a cultura do corpo; lembramos também de Tarcísio Mauro Vago (2012) para pensarmos a Educação Física na cultura escolar e a hegemonia do esporte nessas aulas; e por fim, destacamos a importância das ideias de Marcos Garcia Neira e Mário Luiz Ferrari Nunes (2009) quando eles nos convidam a problematizar as contribuições das teorias pós-críticas para a 
construção do currículo da Educação Física, pensando principalmente nos possíveis diálogos com o pós-estruturalismo, com os estudos culturais e com o multiculturalismo. Tais ideias nos possibilitam pensar nas culturas e nas individualidades dos sujeitos, construindo a partir daí vivências com os jogos e brincadeiras tradicionais que sejam significativas para essas pessoas e levem em consideração os seus saberes sobre eles. Saberes que podem, inclusive, conduzir à produção de novos jogos e brincadeiras característicos daquela cultura.

Acreditamos que a importância de se trabalhar com os jogos e brincadeiras tradicionais nas aulas de Educação Física escolar se dá porque os corpos dos alunos e suas possibilidades de manifestação devem ser refletidos enquanto construção cultural, histórico e social (DAOLIO, 2013). Além disso, Suraya Cristina Darido e Irene Conceição Andrade Rangel (2005, p. 158) dizem que "a Educação Física, ao considerar o jogo conteúdo, colabora para que o mesmo continue a ser transmitido de geração, alicerçando esse patrimônio cultural tão importante para a humanidade".

O Currículo Referência de Minas Gerais (2018) traz também a Unidade Temática "Jogos e Brincadeiras" como um dos saberes que deve ser trabalhado nas aulas de Educação Física, ressaltando a importância de observarmos a cultura popular presente no contexto regional e comunitário. Nesse sentido, o papel do professor de Educação Física escolar é o de buscar edificar significados para a ação deste corpo no mundo, considerando a cultura no qual está arraigado, contribuindo para esse resgate histórico-cultural.

Após refletirmos sobre os conceitos acima citados, salientamos ainda mais a importância que esse conteúdo seja continuado em nossas aulas remotas durante esse momento de isolamento social.

\section{JUSTIFICATIVA}

Observa-se na atualidade que os jogos e brincadeiras tradicionais que fizeram parte da infância de várias gerações estão cada vez menos presentes no cotidiano das crianças. As modificações no ambiente urbano, o aumento da violência, a ausência de praças, espaços e quadras públicas, o advento da internet e, consequentemente, o aumento dos jogos eletrônicos, são fatores que contribuíram para essa mudança. Além disso, nesse momento de isolamento social por causa da pandemia causada pela Covid-19, a tendência é que essas condições se tornem ainda mais desafiadoras. Dessa forma, tornou-se de suma importância realizar um resgate dessas lembranças em nossas aulas remotas para que elas permaneçam em nosso cotidiano, trazendo esta relação de vivência corporal histórica para o momento de isolamento social que foi vivenciado. 
O nosso maior desafio foi escolher quais atividades seriam mais fáceis de serem adaptadas e serem realizadas em casa, visto que algumas questões deveriam ser observadas. Por exemplo, houve uma preocupação com o número de pessoas, já que não poderia haver aglomeração e uma preocupação especial com os materiais que seriam utilizados. Assim, optamos por escolher jogos e brincadeiras que poderiam ser executados sozinhos ou em duplas e, naqueles que precisaria de materiais, que estes fossem fáceis de serem confeccionados com materiais alternativos e/ou reciclados.

Destacamos que não queremos com este texto apontar uma receita ou enaltecer o modelo de ensino a distância, mas sim socializar algo que acreditamos ser possível e potente de ser realizado e replicado em aulas de Educação Física remotas num período em que a indicação das autoridades médicas e científicas fosse de ficar em casa. Nesse sentido, ao longo deste texto iremos compartilhar a experiência pedagógica que realizamos em nossa escola abordando os jogos e brincadeiras tradicionais e como fizemos para adaptá-las para o ensino remoto durante este período.

\section{DESCRIÇÃO DA EXPERIÊNCIA}

A temática dos jogos e brincadeiras tradicionais era trabalhada em várias etapas nas aulas presenciais. Num primeiro momento era apresentado aos estudantes o tema "Jogos e brincadeiras tradicionais", fazendo-se um levantamento sobre quais atividades eles conheciam e se já tinham praticado algumas delas. Posteriormente as crianças faziam uma entrevista com avós, tios, pais, amigos/as ou familiares sobre a infância dessas pessoas. Nessa conversa, eles tinham que relatar e trazer para discussão em sala algumas informações como: o que eles brincavam/jogavam quando eram crianças, como eram essas brincadeiras/jogos, onde eles realizavam essas atividades, quem os ensinou aquela brincadeira e com quem eles brincavam. Na discussão em sala observávamos as brincadeiras/jogos que apareciam mais vezes e quais eram as semelhanças e diferenças das formas de brincar/jogar de cada um dos entrevistados. Após essa discussão era feita uma listagem com todas as brincadeiras/jogos que mais eram citadas. Depois vivenciávamos as/os brincadeiras/jogos mais citadas/os durante as aulas de Educação Física. Entre elas podemos destacar: queimada, piqueesconde, amarelinha, rouba-bandeira, chicotinho queimado, cabra-cega, bola de gude, pular elástico, peteca, bilboquê, pular corda, adoleta, bete, cinco Marias, passar anel, cantigas de roda, dentre outras. No momento final pedíamos aos alunos para fazerem ilustrações e darem explicações sobre as brincadeiras vivenciadas. Sendo estes registros organizados em pastas catálogo com plásticos e deixados à disposição para que fosse consultada por eles. 
Com o desafio de adaptar esse projeto para nossas aulas remotas, tendo em vista o momento de isolamento social que vivenciamos, partimos das atividades presentes nesta pasta para escolhermos quais destas seriam introduzidas no início das nossas aulas no REANP.

Um dos primeiros desafios foi escolher atividades que não precisassem de uma grande quantidade de pessoas para executá-las visto que as crianças só poderiam realizá-las com as pessoas que moravam junto a elas. Assim, optamos por brincadeiras e jogos que poderiam ser realizados individualmente ou em duplas. Focamos também na necessidade de adaptar os objetos utilizados. Enquanto nas aulas presenciais possuímos bolas e materiais disponíveis para todos, nas aulas em casa eles tiveram a oportunidade de aprender a confeccionar seu próprio material. Após essa análise optamos por pique-esconde, amarelinha, chicotinho queimado, cabra-cega, bola de gude, pular elástico, pular corda, adoleta, bete, cinco Marias, peteca, boliche, telefone de copos, aviãozinho e barquinho de papel, jogo da velha e pedra, papel e tesoura, para citar algumas atividades.

No primeiro momento, pedimos às crianças para perguntarem a algum adulto que morava em sua casa sobre as brincadeiras vivenciadas em sua infância. Após essa conversa, eles tinham que relatar ${ }^{5}$ em nossa aula online algumas informações como: O que essas pessoas brincavam/jogavam quando eram crianças? Como eram essas brincadeiras/jogos? Onde essas atividades eram realizadas? Quem os ensinou aquela brincadeira e com quem eles brincavam? Depois desse primeiro momento eles deveriam construir um brinquedo sugerido por nós professores para se divertirem no momento de isolamento social que estavam enfrentando.

Após a realização dessa primeira atividade foi a hora de vivenciarmos os jogos e brincadeiras citados em nossa pasta de atividades e adaptados para o momento atual, enfatizando que caso alguém conhecesse alguma outra atividade ou forma de brincar deveria fazer seu relato em nossos grupos nos aplicativos de troca de mensagens.

Nessas vivências eles puderam jogar/brincar de modo tradicional cada jogo ou brincadeira com seus avós, irmãos, pais e demais pessoas que residiam na mesma casa. Sabendo que todo o processo de adaptação de aulas presenciais para aulas à distância seria um desafio necessário pelo momento atual, notamos que ao procurar essas soluções práticas e aplicáveis tivemos uma resposta satisfatória de nossos discentes.

Para finalizar realizamos em conjunto com toda escola uma festa junina online. Entre muitas outras atividades propostas pelas diversas áreas da escola, propusemos nas aulas de Educação Física

\footnotetext{
${ }^{5}$ Esses relatos foram realizados nos dois aplicativos que utilizamos para fazer contato com as crianças, mães, pais e demais responsáveis: o aplicativo Conexão Escola criado e disponibilizado pela Secretaria de Estado de Educação de Minas Gerais e via WhatsApp. No aplicativo WhatsApp as turmas eram organizadas por grupos, ou seja, cada turma tinha o seu grupo e as discussões sobre as atividades desenvolvidas pelo componente curricular Educação Física eram desenvolvidas ali.
} 
um resgate das brincadeiras tradicionais desse período, sempre ensinando a montar seus próprios elementos com materiais reutilizados. Foi proposto nesse momento, boca do palhaço, tiro ao alvo, jogo de argolas, corrida do ovo e corrida do saco. Foi uma grande festa em nossa escola, onde mesmo de longe pudemos continuar com essa tradição tão importante.

Pedimos aos alunos para que registrassem as atividades através de vídeos ou fotos e enviassem para o grupo criado pela escola no aplicativo WhatsApp. Nele, as crianças tiveram a oportunidade de ver e opinar sobre as diversas produções que foram construídas por elas e seus pares. Consideramos esse contato das crianças com suas produções como algo potente, no sentido em que elas puderam se reconhecer enquanto autoras que brincaram, jogaram e muitas vezes ressignificaram os jogos e brincadeiras tradicionais vivenciados nas aulas de Educação Física.

\section{CONSIDERAÇÕES FINAIS}

Durante a introdução desse conteúdo junto aos nossos estudantes, buscamos apontar a importância dos jogos e brincadeiras tradicionais como instrumentos de apropriação da cultura e reflexão sobre as diferenças entre os anos passados e a atualidade.

Além disso, torna-se fundamental enfatizarmos que assumindo os/as estudantes como sujeitos ativos de todo processo de aprendizagem, desde a liberdade de ressignificar alguma brincadeira até a construção de seus próprios materiais, observamos que muito mais do que apenas reproduzir os movimentos, estes foram capazes de se expressarem conscientemente e realizarem reflexões críticas sobre as práticas vivenciadas e puderam compreender a importância do movimento e da continuidade das atividades Educação Física escolar mesmo à distância.

Consideramos que trabalhar com os jogos e brincadeiras tradicionais com as crianças de forma remota foi uma experiência extremamente potente para nós e, principalmente, para as próprias crianças. Muitas delas tiveram a oportunidade de conhecer algo novo e puderam construir conhecimentos coletivamente junto aos colegas, professores de Educação Física e seus familiares. Pudemos observar a satisfação dos pais, avós, tios e demais familiares em fazer parte das atividades, muitos relembrando as brincadeiras de sua infância. Em um momento difícil de pandemia, notamos que estas atividades trouxeram momentos de alegria e descontração para as famílias. Vimos, por exemplo, avós ensinando aos netos brincadeiras e jogos como cinco Marias, amarelinha, peteca, entre muitas outras. Sabendo que todo o processo de adaptação de aulas presenciais para aulas à distância seria um desafio necessário pelo momento atual, notamos que ao procurar essas soluções práticas e aplicáveis tivemos uma resposta satisfatória de nossos discentes e da comunidade escolar.

Entendemos que o que fica marcado como mais importante nessa prática pedagógica é a experiência que cada um/uma vivenciou, pois para nós experiência é aquilo "que nos passa, o que 
nos acontece, o que nos toca" (LARROSA, 2002, p. 21). Assim, ao sermos tocados pela experiência, vamos sendo transformados pelo seu saber, pensando que trabalhar com os jogos e brincadeiras tradicionais durante as aulas remotas de Educação Física também se configura enquanto processo educativo que marcou, subjetivou e produziu experiências aos sujeitos envolvidos nessa prática. Nesse sentido, concordamos com Tarcísio Mauro Vago (2012, p. 69) e acreditamos "na Educação Física na escola como um tempo de enriquecer a experiência humana. Experiências do corpo. Experiências no corpo. Experiências com o corpo". Experiências, que na proposta deste trabalho, potencializaram ricas vivências com os jogos e brincadeiras tradicionais mesmo num momento excepcional de pandemia e isolamento social.

\section{REFERÊNCIAS}

COLETIVO DE AUTORES. Metodologia do Ensino de Educação Física. São Paulo: Cortez, 2012.

DAOLIO, Jocimar. Educação Física e Cultura. Revista Corpoconsciência, Cuiabá, n. 01, p. 11-18, 1998.

DAOLIO, Jocimar. Da cultura do corpo. 17ª edição. Campinas: Papirus, 2013.

DARIDO, Suraya Cristina; RANGEL, Irene Conceição Andrade. Educação Física na escola: implicações para a prática pedagógica. Rio de Janeiro: Guanabara Koogan, 2005.

FISCHER, Rosa Maria Bueno. O dispositivo pedagógico da mídia: modos de educar na (e pela) TV. Educação e Pesquisa, São Paulo, v. 28, n. 1, jan./jun. 2002, p. 151-162.

KISHIMOTO, Tizuko Morchida. O jogo e a educação infantil. São Paulo: Pioneira, 2003.

LARROSA, Jorge. Notas sobre a experiência e o saber da experiência. Revista Brasileira de Educação, São Paulo, n. 19, p. 20-28, jan/abr. 2002.

MARCELlinO, Nelson Carvalho. Estudos do Lazer: uma introdução. $5^{\text {a }}$ edição. Revista Campinas, São Paulo: Autores Associados, 2012.

MINAS GERAIS. Currículo Referência De Minas Gerais. Belo Horizonte,MG, 2018. Disponivel em: http://bit.ly/2OUZkee. Acesso em: 30 jul.2020

NEIRA, Marcos Garcia; NUNES, Mário Luiz Ferrari. Educação Física, currículo e cultura. São Paulo: Phorte, 2009.

VAGO, Tarcísio Mauro. Educação Física na escola: para enriquecer a experiência da infância e da juventude. Belo Horizonte: Mazza Edições, 2012. 